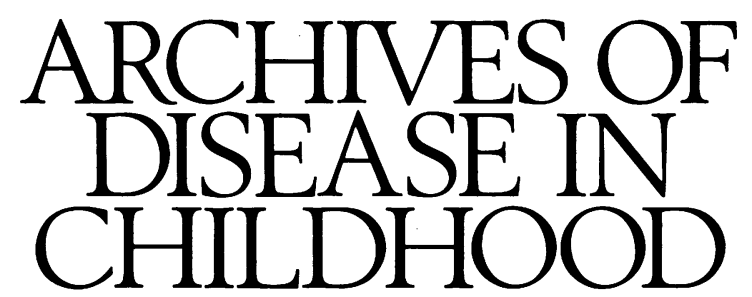

The fournal of the British Paediatric Association

\title{
Annotation
}

\section{New insights into the haemolytic uraemic syndromes}

The haemolytic uraemic syndromes comprise a heterogeneous group of disorders in which microangiopathic haemolytic anaemia, thrombocytopenia, and acute renal failure occur together. In the last annotation in this journal on the subject, Levin and Barratt pointed out an important separation into two broad subgroups. ${ }^{1}$ The first is a disorder which has become increasingly common and at present affects approximately 150 children each year in the United Kingdom. It typically follows a prodromal illness of diarrhoea (often bloody), occurs more often in the summer months, and $85 \%$ of these children can be expected to make a good recovery. This contrasts appreciably with a much rarer illness in which there is no obvious prodrome and no seasonal incidence. In this heterogeneous group one finds patients with a relapsing form of the disease or a positive family history; more than $70 \%$ progress to chronic renal failure. The mnemonics ' $D+$ ' for diarrhoea associated and ' $D-$ ' for the non-prodromal forms of the syndrome are gaining acceptability, and reflect an extrinsic or intrinsic aetiology respectively. Although a wide variety of pathogens have been associated with the $\mathrm{D}+$ form, no predominant agent was identified until recently.

The discovery by Karmali et al in 1983 that Verocytotoxin producing Escherichia coli (VTEC) were implicated in cases of D+ haemolytic uraemic syndrome was a breakthrough. ${ }^{2}$ Konowalchuk et al are credited with identifying this novel exotoxin from $E$ coli which proved lethal to Vero cells, an epithelial cell line derived from kidney of the green monkey. ${ }^{3}$ Since then, studies with both antibodies and genomic probes have shown that there are two closely related but distinct exotoxins. The first, Verocytotoxin-1 (VT1) is identical to Shiga toxin produced by Shigella dysen- 
teriae type $1,{ }^{4}$ and the second, VT2, exhibits $58 \%$ genetic homology and 55-60\% amino acid homology with VT1. For this reason some authors refer to VT1 and VT2 as Shiga-like toxin 1 and 2 respectively. The toxins consist of a central A-subunit and five B-subunits which bear receptors for the terminal disaccharide galactose-( $\alpha 1-4 \beta)$-galactose which requires a sphingosine base for successful Verocytotoxin binding. ${ }^{6}$ In man this conformation occurs in the cell membrane glycoprotein $\mathrm{Gb} 3$ (the blood group antigen $\mathrm{Pk}$ ) and in P1, another component of the P blood group system. After binding to the cell surface (see figure) endocytosis takes place and the A-subunit is released into the cytosol. Here it is proteolytically cleaved to an $A_{1}$ fragment which binds to $60 \mathrm{~S}$ ribosomes and blocks RNA transcription, preventing protein synthesis and killing the cell. The $A_{1}$ fragment acts enzymatically and therefore has the potential to be highly injurious at very low dosage. ${ }^{7}$

VTEC of serotype 0157:H7 have been implicated in haemorrhagic colitis in man, and it is of note that the prodrome experienced by children with haemolytic uraemic syndrome very often is one of bloody diarrhoea and abdominal pain. Small bowel involvement is uncommon. By combining three laboratory methods (recovery of VTEC or neutralisable free Verocytotoxin in faeces, and a rise in antibody titre to Verocytotoxin) Karmali et al found evidence of VTEC infection in an estimated $75 \%$ of Canadian children with D+ haemolytic uraemic syndrome. ${ }^{8}$ Elsewhere in this issue we report a collaborative study by the British Association for Paediatric Nephrology (BAPN), the Communicable Disease Surveillance Centre, and the Division of Enteric Pathogens of the Public Health Laboratory in which DNA probes were applied to faecal samples from children with haemolytic uraemic syndrome. ${ }^{9}$ This work confirmed the association between VTEC and D+ haemolytic uraemic syndrome in the United Kingdom and showed that although serotype $0157: \mathrm{H} 7$ is most commonly associated, other serotypes can also be found. Interestingly there was a predominance of VT2 producing organisms, and similar observations were made recently in both Germany and North America. ${ }^{10} 11$

It is well recognised that glomerular endothelium is the main site of injury in haemolytic uraemic syndrome. How far can our present understanding of the action of Verocytotoxin explain the pathogenesis? Verocytotoxin is lethal to human umbilical vein endothelium in vitro, but this is best seen when the cells are proliferating. ${ }^{1213}$ In normal blood vessels endothelial cells replicate very slowly and so far no direct experiments on growth arrested human glomerular endothelium have been performed. The injection of Verocytotoxin into the usual laboratory animals does not provoke the disease, probably because they lack the appropriate toxin receptors within the kidney, unlike human kidney cortex which is known to express Gb3. ${ }^{14}$ The erythrocyte expression of blood group antigen $\mathrm{Pl}$ is heterogenous in man. We found a larger than expected proportion of patients with $\mathrm{D}+$ haemolytic uraemic syndrome to be either Pl negative or only weakly positive, those with the most severe disease having the least expression. ${ }^{15}$ This suggests that the capacity of red cells to bind Verocytotoxin may serve as a buffer by reducing endothelial exposure to the toxin and consequent renal damage, and indirectly supports the role of Verocytotoxin.

Given the similarity between Verototoxins and Shiga toxin, it is not surprising that there are clinical features common to the forms of haemolytic uraemic syndrome induced by VTEC and $S$ dysenteriae type 1 . In shigellosis, endotoxaemia and a leukaemoid response have been shown to be risk factors for the development of haemolytic uraemic syndrome. ${ }^{1617}$ Recently Walters et al described a strong association between neutrophilia at onset and adverse out- come in patients with $\mathrm{D}+$ haemolytic uraemic syndrome from south east England. ${ }^{18}$ This has been confirmed both in the national study 9 and in a retrospective series from the Children's Hospital, Birmingham (N A G Coad, T Marshall, B Rowe, et al, unpublished observations). Interestingly, in the latter the association only applied to patients presenting after 1981 , and this combined with an abrupt increase in numbers and a change in clinical variables (age, nature of prodrome, outcome) suggested the arrival of VTEC at that time. Observations that neutrophils from patients with haemolytic uraemic syndrome showed increased adhesion to endothelium in vitro, ${ }^{19}$ that plasma elastase is increased in the acute phase of the syndrome and that by electron microscopy peripheral blood neutrophils appear degranulated, ${ }^{20}$ suggest that the neutrophil has an important role in the pathogenesis.

It is not known whether the neutrophil response can be attributed to the action of Verocytotoxin per se. More is known, at least in theory, about the actions of endotoxin, the lipopolysaccharide derived from the bacterial cell wall. Given the florid colitis that affects many of these patients, absorption of bacterial endotoxin is likely but has not yet been studied in VTEC disease. Endotoxin acts by altering the surface characteristics of endothelial cells via the secretion of cytokines (notably tumour necrosis factor and interleukin-1), rendering them procoagulant and adhesive for neutrophils. ${ }^{21}{ }^{22}$ In the intact animal leucopenia induced by busulphan has been shown to prevent the generalised Shwartzman reaction, which in rabbits resembles haemolytic uraemic syndrome. ${ }^{23}$ The pivotal role of neutrophils in an endotoxin model of haemolytic uraemic syndrome has been shown by experiments in which granulocytes transferred from a lipopolysaccharide treated animal induce vasculopathy in a recipient which itself has not been exposed to endotoxin. ${ }^{24}$ Further studies will be necessary to define the separate roles of Verocytotoxin and endotoxin in the human disorder and explore the possibility that there may be synergism between these two agents.

What practical points can paediatricians glean from this evolving story? Firstly the increased prevalence of $\mathrm{D}+$ haemolytic uraemic syndrome is such that a paediatric department in a district general hospital is likely to diagnose a new case every two years. Because much morbidity can be induced by inappropriate rehydration in patients whose renal function is compromised it is essential to arrive at the diagnosis as soon as possible. ${ }^{25}$ We therefore recommend that preschool children admitted with acute bloody diarrhoea not only have close attention paid to weight and urine output, but also monitoring of plasma sodium, potassium, and creatinine concentrations. The appearance of fragmented red cells on a peripheral blood film strongly suggests the onset of the syndrome. Local public health laboratories are increasingly interested to examine faeces for VTEC, though most utilise the non-fermentation of sorbitol to screen for the 0157:H7 serotype. As this serotype only accounts for approximately $75 \%$ of VTEC in the United Kingdom, a high false negative rate is inherent in the method. The wider availability of gene probes for rapid identification of Verocytotoxin producing organisms, augmented by the development of serological techniques, ${ }^{26}$ should enable a higher pick up rate.

With careful attention to water and electrolyte requirements many patients with haemolytic uraemic syndrome can be nursed successfully to the recovery phase without the need for dialysis. However, if at onset the child is shocked or has a neutrophil crunt of $>20 \times 10^{9} / 1$ a difficult course lies ahead and early :eferral to a paediatric nephrology service is indicated. During the acute illness, careful observations are needed to identify extrarenal manifestations such as encephalopathy, diabetes mellitus, or cardiomyo- 
pathy. ${ }^{27-29}$ Finally, one should distinguish the rare patient with the non-prodromal, $\mathrm{D}$ - form of the syndrome, perhaps presenting with pallor and found to have proteinuria, hypertension, or renal impairment. These also deserve a nephrological consultation because of their adverse prognosis and complexity of treatment.

Department of Nephrology,

D V MILFORD

The Children's Hospital,

Ladywood Middleway,

Ladywood,

Birmingham B16 8ET

1 Levin M, Barratt TM. Haemolytic uraemic syndrome. Arch Dis Child 1984; 59:397-400.

2 Karmali MA, Steele BT, Petric M, Lim C. Sporadic cases of haemolytic uraemic syndrome associated with faecal cytotoxin and cytotoxin-producing Escherichia coli in stools. Lancet 1983;i:619.

3 Konowalchuk J, Speirs JI, Stavric S. Vero response to a cytotoxin of Escherichia coli. Infect Immun 1977;18:775-9.

4 O'Brien AD, LaVeck GD. Purification and characterization of a shigella dysenteriae 1-like toxin produced by Escherichia coli. Infect Immun 1983, 40:675-83.

5 Jackson MP, Neill RJ, O'Brien AD, Holmes RK, Newland JW. Nucleotide sequence analysis and comparison of the structural genes for Shiga-like toxin 1 and Shiga-like toxin 2 encoded by bacteriophages from Escherichia coli 933. FEMS Microbiology Letters 1987;44:109-14.

6 Lingwood CA, Law H, Richardson S, et al. Glycolipid binding of purified and recombinant Escherichia coli produced verotoxin in vitro. $\mathcal{J} \mathrm{Biol}$ Chem recombinant Esch

7 Endo Y, Tsurugi K, Yutsudo T, Takeda Y, Ogasawara T, Igarashi K. Site of action of a Verotoxin (VT2) from Escherichia coli 0157:H7 and of Shiga action of a Verotoxin (VT2) from Escherichia coli 0157:H7 and of
toxin on enkaryotic ribosomes. Eur $\mathcal{F}$ Biochem 1988;171:45-50.

8 Karmali MA, Petric M, Lim C, Fleming P, Arbus G, Lior H. The association between idiopathic hemolytic uremic syndrome and infection by verotoxin producing Escherichia coli. F Infect Dis 1985;151:775-82.

9 Milford DV, Taylor CM, Guttridge B, Hall S, Rowe B, Kleanthous H. Haemolytic uraemic syndromes in the British Isles 1985-8: association with Verocytotoxin producing Escherichia coli. Part 1: clinical and epidemiological aspects. Arch Dis Child 1990;65:716-21.

10 Bitzan M, Karch H, Klemt M, Buren J, Altrogge H. Relevance of verotoxin mediated haemolytic uremic syndrome in Germany. Nieren-und Hochdruck Krankheiten 1988;17:246.
11 Tarr P, Neill M, Clausen C, Newland J, Neill R, Moseley S. Genotypic variation in pathogenic Escherichia coli 0157:H7 isolated from patients in Washington, 1984-87. F Infect Dis 1989;159:344-7.

12 Obrig TG, Del Vecchio PJ, Karmali MA, Petric M, Moran TP, Judge TK. Pathogenesis of haemolytic uraemic syndrome. Lancet 1987;ii:687.

13 Kavi J, Chant I, Maris M, Rose PE. Cytopathic effect of verotoxin on endothelial cells. Lancet 1987;ii:1035.

14 Boyd B, Lingwood C. Verotoxin receptor glycolipid in human renal tissue. Nephron 1989;51:207-10.

15 Taylor CM, Milford DV, Rose PE, Roy TC, Rowe B. The expression of blood group P1 in post-enteropathic haemolytic uraemic syndrome. Pediatric Nephrology 1990;4:59-61.

16 Koster F, Levin J, Walker L, et al. Hemolytic uremic syndrome after shigellosis-relation to endotoxemia and circulating immune complexes. $N$ Engl f Med 1978;298:927-33.

17 Butler T, Islam M, Azad M, Jones P. Risk factors for development of hemolytic uremic syndrome during shigellosis. $f$ Pediatr 1987;110:894-97.

18 Walters MD, Matthei U, Kay R, Dillon MJ, Barratt TM. The polymorphonuclear count in childhood hemolytic uremic syndrome. Pediatric Nephrology 1989;3:130-4.

19 Forsyth KD, Fitzpatrick M, Simpson A, Barratt TM, Levinsky R. Neutrophil-mediated endothelial injury in haemolytic uraemic syndrome. Lancet 1989;ii:411-4.

20 Milford DV, Taylor CM, Rafaat F, Halloran E. Neutrophil elastases and haemolytic uraemic syndrome. Lancet 1989;ii: 1153.

21 Schleimer RP; Rutlidge BK. Cultured human vascular endothelial cells acquire adhesiveness for neutrophils after stimulation with interleukin l, endotoxin and tumor-promoting phorbol diesters. F Immunol 1986;136: 649-54

22 Stern D, Bank I, Nawroth P, et al. Self-regulation of procoagulant events on the endothelial cell surface. $\mathcal{F}$ Exp Med 1985;162:1223-35.

23 Butler T, Rahman H, Al-Mahmud KA, et al. An animal model of haemolyticuraemic syndrome in shigellosis: lipopolysaccharides of shigella dysenteriae 1 and $S$ flexneri produce leucocyte-mediated renal cortical necrosis in rabbits. Br f Exp Pathol 1985;66:7-15.

24 Niemetz J, Fani K. Thrombogenic activity of leukocytes. Blood 1973;42: 47-59.

25 Milford DV, Taylor CM. Hyponatraemia and haemolytic uraemic syndrome. Lancet 1989;i:439.

26 Chart H, Scotland SM, Smith HR, Rowe B. Antibodies to Escherichia coli 0157 in patients with haemorrhagic colitis and haemolytic uraemic syndrome. F Clin Pathol 1989;42:973-6.

27 Upadhyaya K, Barwick K, Fishaut M, Kashgarian M, Siegel N. The importance of nonrenal involvement in hemolytic-uremic syndrome. Pediatrics ance of nonrenal

28 Taylor CM, White RHR, Winterborn MH, Rowe B. Haemolytic-uraemic syndrome: clinical experience of an outbreak in the West Midlands. $\mathrm{Br}$ Med F 1986;292:1513-6.

29 Poulton J, de Giovanni J, Taylor CM. Dilated cardiomyopathy associated with haemolytic uraemic syndrome. Br Heart f 1987;57:181-3. 